\title{
Effect of daily short term and high intensity training to the metabolic function in college sport student
}

\author{
Mizuki Nakajima ${ }^{1}$, Takeshi Sato ${ }^{2 *}$ and Yousuke Takeishi ${ }^{3}$ \\ ${ }^{1}$ Graduate School of Arts and Sciences, The University of Tokyo, Japan \\ 2Jissen Women's University, Tokyo, Japan \\ ${ }^{3}$ Kyusyu Institute of Information Science,Fukuoka, Japan
}

\begin{abstract}
Background: Physical exercise is particularly important as one of the habits with most influence in the control of obesity. The purpose of this study was to investigate of the blood in the obesity students with high intensity training performed as Sumo, Japanese-style wrestling.

Methods: It was participated twenty-five top level male Sumo wrestling players who belong to university association of Sumo in Japan (mean \pm SD; age:21.04 \pm 0.98 years old ; height $174.0 \pm 0.06 \mathrm{~cm}$; weight $116.52 \pm 24.28 \mathrm{~kg}$; BMI $38.31 \pm 7.45 \mathrm{~kg} / \mathrm{m}^{2}$ ) and compared eight volunteer students without fitness habits (mean \pm SD; age: $21.50 \pm 2.27$ years old; height $162.0 \pm 0.09 \mathrm{~cm}$; weight $57.03 \pm 9.15 \mathrm{~kg}$; BMI $21.44 \pm 1.25 \mathrm{~kg} / \mathrm{m}^{2}$ ) as control group participated in this study. It was performed examination of the blood below: albumin, Albumin/Globulin ratio, Glycoalbumin, cholesterol, total protein.

Result: It was clearly significant difference in BMI between Sumo wrestling group and control group. However, all subjects were within the reference values in both groups in cholesterol (Sumo wrestling: $181.64 \pm 28.49 \mathrm{mg} / \mathrm{dl}$, control student: $176.57 \pm 25.87 \mathrm{mg} / \mathrm{dl}$ ), total protein (Sumo wrestling: $7.48 \pm 0.38 \mathrm{~g} / \mathrm{dl}$, control student: $7.53 \pm 0.35 \mathrm{~g} / \mathrm{dl})$.

Discussion: It was suggested that it was the improvement of obesity by short-term and high intensity training. The major finding was that high intensity physical exercise was to maintain at reference values by blood test in young obesities. Sumo wrestling players were training for resistance and aerobic two hours per day. It was shortly exercise duration than other sports competition with routine exercise. It was performed high intensity exercise training as integrated resistance and aerobic training to keep health conditions. Overall, physical activity is a highly effective prescription for the prevention and management of health conditions.
\end{abstract}

\section{Introduction}

Obesity increases the risk of a number of health conditions including hypertension, adverse lipid concentrations, and type 2 diabetes. Especially, almost 41 million women and more than 37 million men aged 20 and over were obese in United State [1-3]. WHO reported that the obesity population of the world has increased rapidly from 1975 to 40 years, and the obesity population reached 641 million people (266 million men, 375 million women). In addition, the proportion of obesity was announced that men increased to $11 \%$ more than three times, women rose to $15 \%$ more than twice [4]. Body Mass Index (BMI) has been generally used as one of the indicators to evaluate obesity.

Physical exercise is particularly important as one of the habits with most influence in the control of obesity [5]. Exercise underpin the risk of obesity-related metabolic disease. "Any bodily movement produced by the contraction of skeletal muscle that increases energy expenditure above a basal level. Physical activity generally referred to the subset of physical activity that enhances health", as defined by Centers for Disease Control and Prevention [6]. It was reported that the body rapidly became maladaptive to insufficient physical activity and continues, both the total number and the quality of life were greatly decreased. There was definitive evidence that physical inactivity was one of the important causes of most chronic diseases. In addition, chronic diseases were not necessarily the inevitable consequences of life, since physical activity predominantly preventes or was delaied chronic diseases $[7,8]$. There were not enough data between obese $(\mathrm{BMI}>25)$ and high intensity physical training for health checking diagnosis.
Sumo was a traditional Japanese competition. Sumo wrestling was unique in combat sport, and in all of sport. To win in sumo, one must push one's opponent out of the ring, or cause the opponent to touch the ground with any part of the body except the soles of the feet. Sumo could advance the competition to dominance by increasing the weight from the characteristics of the game. Sumo wrestling players generally have many players with $\mathrm{BMI}>25$, due to their competitive characteristics. In addition, their practice was a high intensity exercise for 2 hours a day as a short time. Sumo practice included aerobic exercise and anaerobic exercise (Figures 1-3). Sumo had characteristics daily practices. For example, "Teppou" was the exercise that moves both hands and feet alternately towards the pillar (Figure 1). "Shiko" was pushing the both arm with assumed sqatting position. It was one of basic movement to stabilize the center of gravity and train their legs. This exercise was a resistance exercise (Figure 2). "Moushiai" was the skill to point out a partner with palm of the hand. In the winning style, the winning wrestler nominated the next opponent, practicing while changing the opponent. This practice repeated short term exercise, including elements of aerobic and anaerobics exercise (Figure 3 ).

Correspondence to: Takeshi Sato, Ph.D, Lab.Ergonomics, Jissen Women's University, 4-1-1, Osakaue, Hino, Tokyo 191-8510, Japan, Tel: 810425858895 ; Fax: 810425858895; E-mail: sato-takeshi@jissen.ac.jp

Key words: short term high intensity training, metabolism, obesity

Received: March 29, 2018; Accepted: April 23, 2018; Published: April 27, 2018 


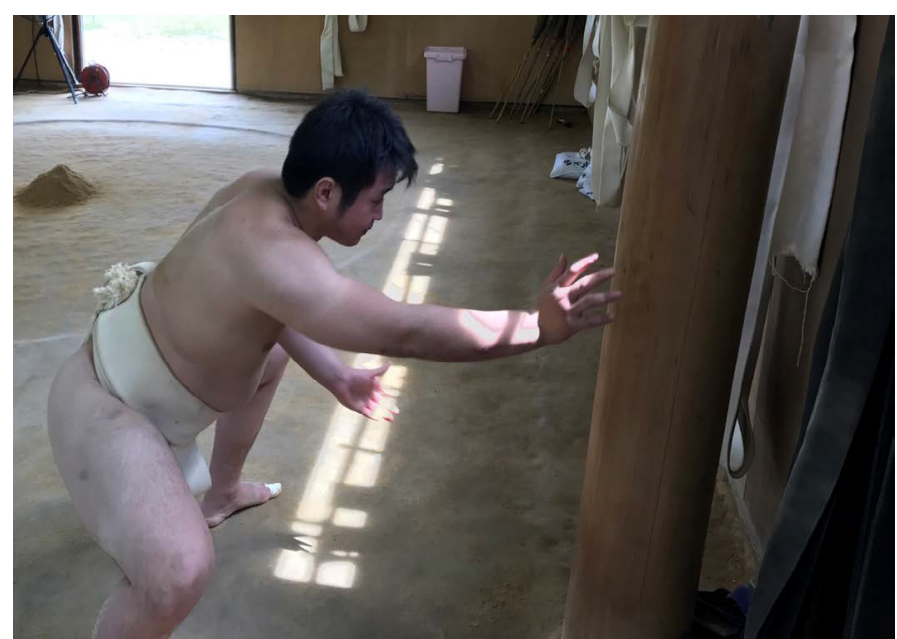

Figure 1. Example of Sumo westling trainning, called "Teppou". It was exercise that moves both hands and feet alternately towards the pillar.

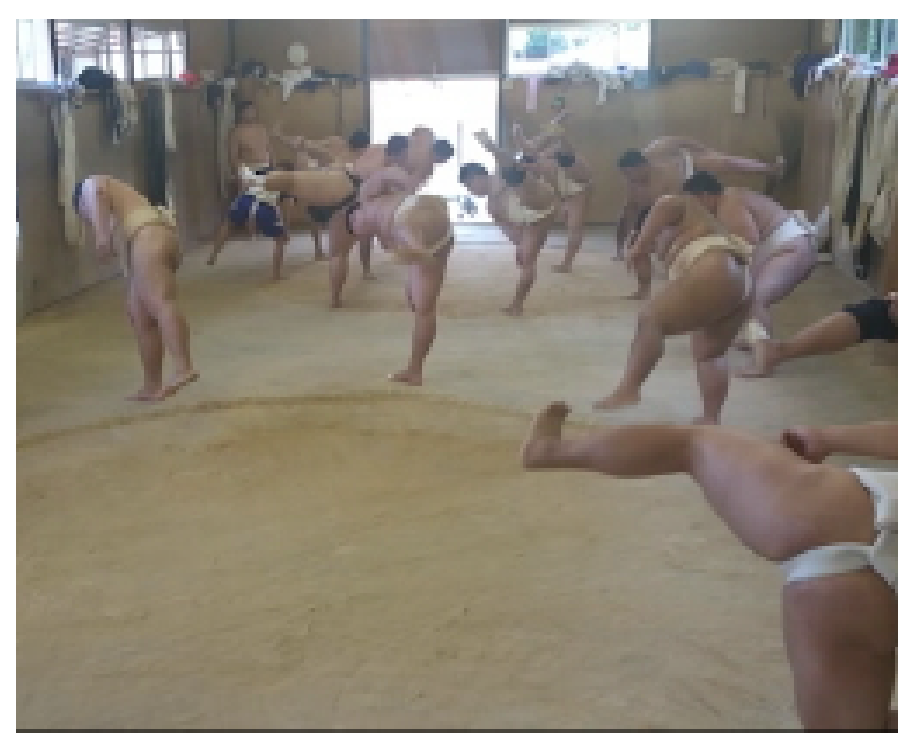

Figure 2. Example of Sumo westling trainning, called "Shiko" pushing the both arm with assumed sqatting position.

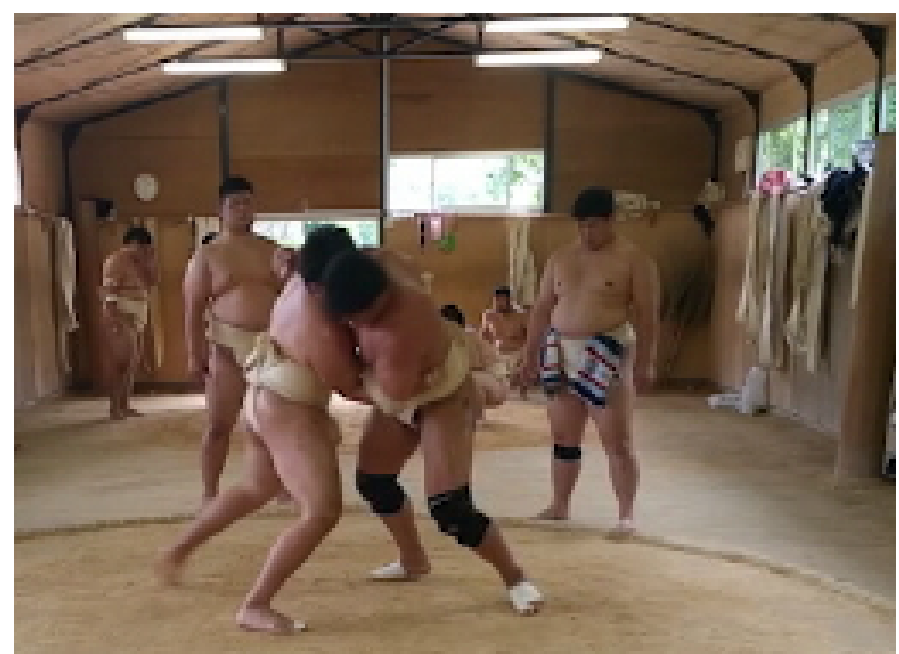

Figure 3. Example of Sumo westling trainning, called "Moushiai". The skill to point out a partner with palm of the hand.
Matthew et al. showed that they had high absolute VO2max, aerobic capacity $[9,10]$. It was reported the study of energy supply ratio (ratio of oxygen intake and oxygen debt) of the short term and high-intensity exercise. Medbø and Tabata(1989) examined a metabolism reply during the high-intensity bicycle exercise that fatigue was developed in 30 seconds, 1 minutes, 2 -3 minutes. And the aerobic energy supply ratio reported that it was $30 \pm 1 \%, 47 \pm 2 \%$, $65 \pm 2 \%$ each. In addition, it was reported that the energy supply ratio changed logarithmically depending on exercise time [11]. In recent years, it has been revealed that it were effects of reducing visceral fat and improving blood glucose by high intensity exercise $[12,13]$. The mechanism of acute hypoglycemia due to exercise was thought to involve insulin-independent glucose uptake in muscle. It was the most important purpose of exercise therapy that training effect by accumulation of exercise therapy, that is, improvement of insulin resistance of exercise therapy. It was contributed to the prevention and improvement of lifestyle-related diseases such as metabolic syndrome, hypertension, dyslipidemia, nonalcoholic fatty liver diseases as well as diabetes. Exercise was glucose-dependent insulinotropic polypeptide (GIP, glucagon-like peptide 1: GLP-1) secretion, increased glucose insulin secretion, and improved glucose metabolism [14]. Exercise therapy could expect hypoglycemic effect as an acute effect. In recent years, postprandial hyperglycemia affected the vascular endothelium and leads to the risk of developing atherosclerosis, so it was considered important to suppress the rise in blood glucose after meals and reduce the fluctuation in blood circulation daily.

The purpose of this study was to investigate of themetabolic function in the obesity students with short term and high intensity training performed as Sumo, Japanese-style wrestling.

\section{Methods}

We computed BMI as the ratio between weight $(\mathrm{kg})$ and height $\left(\mathrm{m}^{2}\right)$. It was participated twenty-five top performance male Sumo wrestling players who belong to university association of Sumo in Japan (mean $\pm S D$; age: $21.04 \pm 0.98$ yeares old; height $174.0 \pm 0.06 \mathrm{~cm}$; weight $116.52 \pm 24.28 \mathrm{~kg}$; BMI $38.31 \pm 7.45 \mathrm{~kg} / \mathrm{m}^{2}$ ) and compared eight volunteer students without fitness habits (mean \pm SD; age: $21.50 \pm 2.27$ yeares old; height $162.0 \pm 0.09 \mathrm{~cm}$; weight $57.03 \pm 9.15 \mathrm{~kg}$; BMI $21.44 \pm 1.25 \mathrm{~kg} / \mathrm{m}^{2}$ ) as control group participated in this study (Table 1). Sumo wrestling students meant a student who has been an average BMI value of 25 or more and has carried out 2 hours / day short time high intensity exercise least 5 times per week. The control group meant a general college student who did not have exercise habits. It was performed examination of the blood below: Albumin (ALB), Albumin/ Globulin ratio, Glycoalbumin, cholesterol, total protein. All data were corected their optinally.

Table1. Background of participants

\begin{tabular}{|c|c|c|}
\hline & $\begin{array}{c}\text { Sumo wrestling Students } \\
(\mathrm{n}=25)\end{array}$ & Control Students $(\mathrm{n}=8)$ \\
\hline Age & $21.04 \pm 0.98$ & $21.50 \pm 2.27$ \\
\hline Height $(\mathrm{cm})$ & $174.0 \pm 0.06$ & $162.0 \pm 0.09$ \\
\hline Weight $(\mathrm{kg})$ & $116.52 \pm 24.28$ & $57.03 \pm 9.15$ \\
\hline BMI $\left(\mathrm{kg} / \mathrm{m}^{2}\right)$ & $38.31 \pm 7.45$ & $21.44 \pm 1.25$ \\
\hline
\end{tabular}

\section{Statistical analysis}

Experimental data were expressed as mean values with standard deviation. BMI data of statistical analysis was used two-way analysis of variance (ANOVA). Statistical significance was considered at $\mathrm{p}<0.05$ by using SAS. 


\section{Result}

There was a significant difference in the BMI val ue between the Sumo wrestling and control groups (Figure 4). As a result of the multiple comparisons, it were not significant difference that Total Protein and Albumin to globulin ratio and cholesterol experiment between two groups (Figures 5-8). There were reference values in cholesterol (Sumo wrestling: $181.64 \pm 28.49 \mathrm{mg} / \mathrm{dl}$, control student: $176.57 \pm 25.87 \mathrm{mg} /$ $\mathrm{dl}$ ), total protein (Sumo wrestling: $7.48 \pm 0.38 \mathrm{~g} / \mathrm{dl}$, control student: $7.53 \pm 0.35 \mathrm{~g} / \mathrm{dl}$ ), Albumin to globulin ratio (Sumo wrestling: $1.67 \pm 0.20$, control student: $1.78 \pm 0.19$ ), Alubmin (Sumo wrestling: $4.67 \pm 0.32 \mathrm{mg} /$ $\mathrm{dl}$, control student: $4.78 \pm 0.25 \mathrm{mg} / \mathrm{dl}$ ) for all subjects. There was no significant difference between Sumo wrestling and control student. In addition, those was indicated within the standard value published by the Japanese Red Cross Society.

\section{Discussion}

This study was to investigate the effect of High Intensity and Short time exercise in obesity. It was significantly different in BMI between the two groups (Figure 4). It were reported that Total Protein and Albumin to globulin ratio and cholesterol were not significant difference. This result was shown that it was unlikely to be abnormal in biochemical indices for obese people with exercise habits.

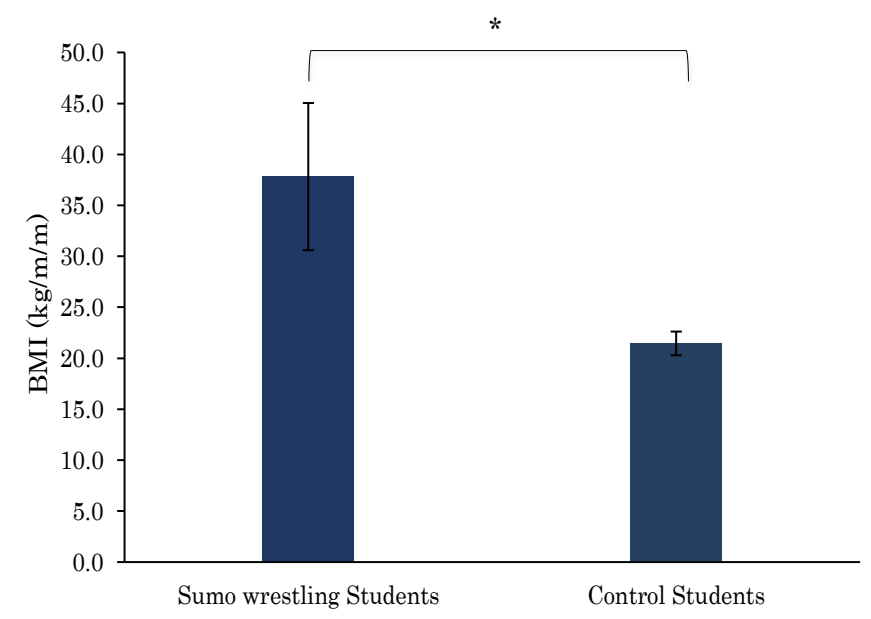

Figure 4. Comparison of BMI Sumo wrestling and control student group *: $p<0.05$

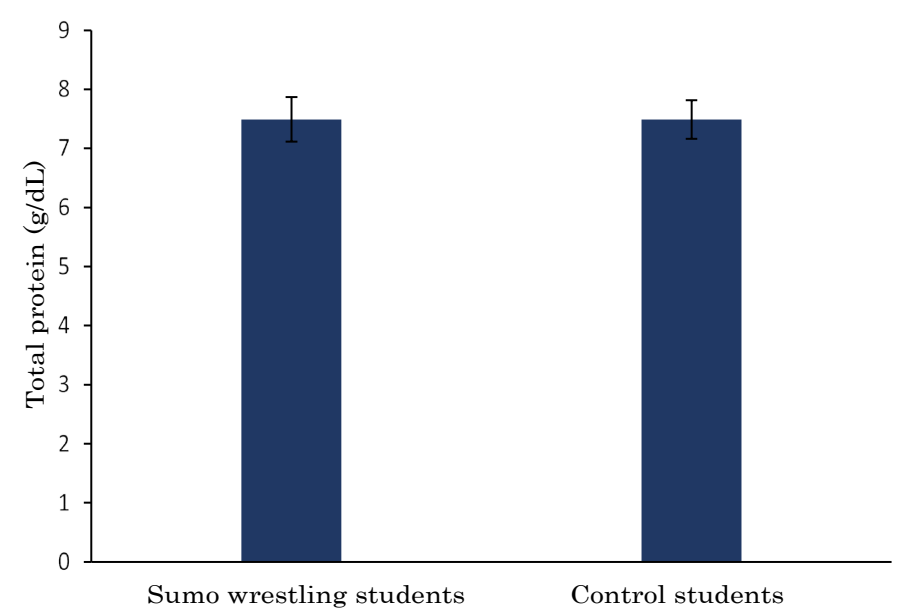

Figure 5. Comparison of Total Protein (TP) Sumo wrestling and control student group

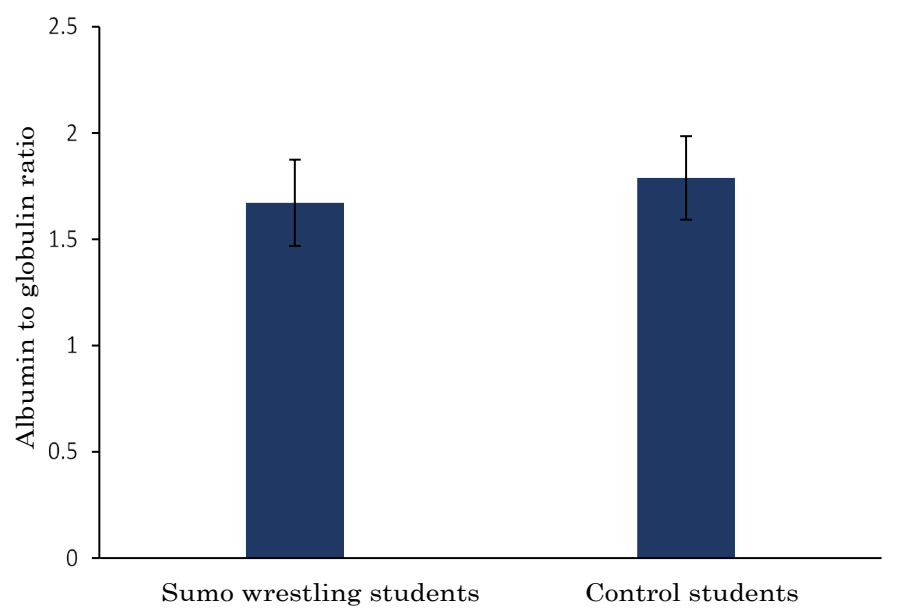

Figure 6. Comparison of Albumin to globulin ratio Sumo wrestling and control students group

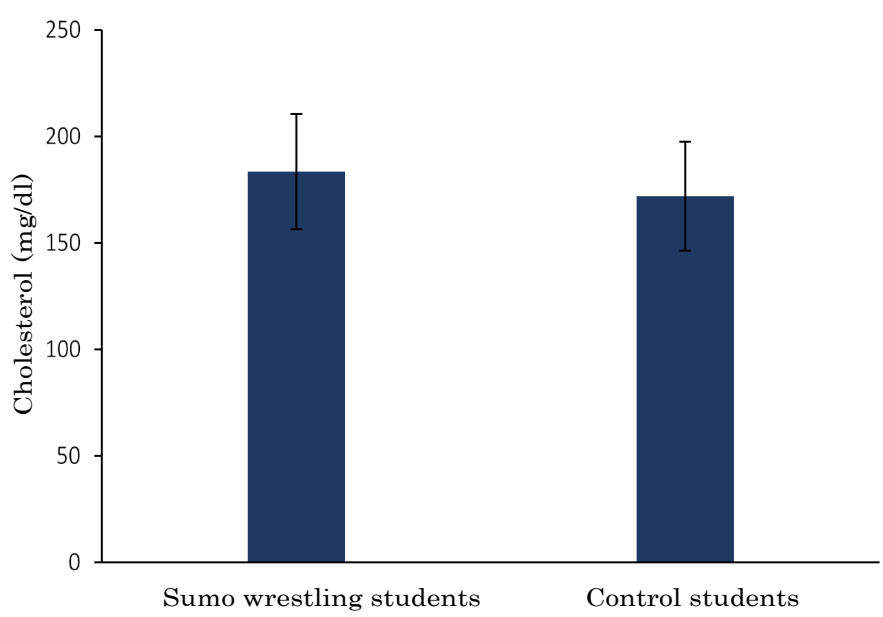

Figure 7. Comparison of Cholesterol Sumo wrestling and control students group

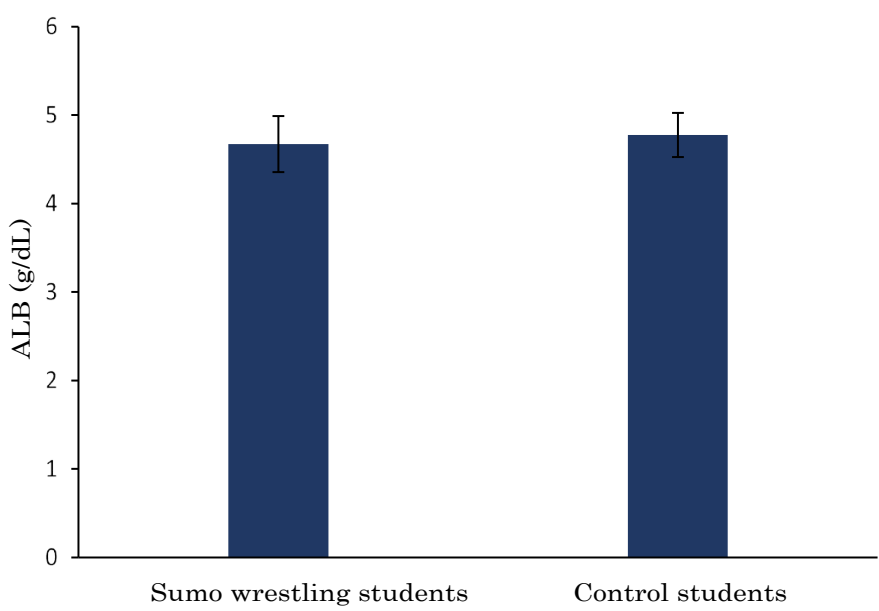

Figure 8. Comparison of Albumin (ALB) Sumo wrestling and control students group

Obesity was one of the leading causes of preventable morbidity and mortality from chronic diseases. Finucane et al. reported that the prevalence of obesity worldwide nearly doubled over the last three decades [15]. The BMI cutoff thresholds for adults were originally proposed in light of data indicating increased risks across the 
overweight range for associated medical disorders such as metabolic syndrome [16]. Obesity, glucose intolerance, and hypertension in childhood were strongly related with increasing rates of premature death from endogenous causes in this population. It was showed that childhood hypercholesterolemia was not a major predictor of premature death from endogenous causes [17]. In this study, there was a significant difference in BMI between healthy volunteers and sumo players (Figure 4).

The benefits fo or utine exercise in improving SA CVD (atherosclerotic cardiovascular disease) risk factors and prevention of obesity have been well established [18]. Denou et al. reported that repeated exercise provided metabolic benefits during obesity [19]. They assessed if exercise could oppose changes in the taxonomic and predicted metagenomic characteristics of the gut microbiota during diet-induced obesity. In addition, their results showed that repeated exercise training can overcome a distinct subset of the changes in the distal gut and fecal microbiota caused by high-fat diet(HFD)-induced obesity, independently of changes in body mass or fat mass. It was increased the predicted genetic capacity related to the TCA cycle among other aspects of metabolism by exercise training .

Lee et al. indicated that the group with moderate to high intensity (such as fast walking) had a lower risk of mortality of $60-70 \%$ than the group that was least active. It was supported that the benefit of exercise criteria such as the 2008 American Heart Association Guidelines for Physical Activity (Aerobic exercise with medium intensity exercise for at least 150 minutes or 75 minutes high intensity exercise, and strength training over 2 days per week) [20]. These results supported that there were no significant difference in blood biochemical indices between healthy volunteers and sumo wrestlers(BMI>25) (Figures 4-8).

\section{Acknowledgment}

Experiments data were submitted by their own medeical test data optionally. All authors appreciate all subjects and read the manuscript and approved the final version. All the authors had responsibilities for the final content.

\section{References}

1. Skinner AC, Perrin EM, Skelton JA (2016) Prevalence of obesity and severe obesity in US children, 1999-2014.Obesity 24: 1116-1123. [Crossref]

2. Ahmadi M, Moosazadeh M, Vardanjani HM, Dehghan A (2014) Prevalence of obesity and overweight and their related factors among the adults of Mazandaran Province, Iran, in 2010. Electron Physician 6: 955-961. [Crossref]

3. Kumah DB, Akuffo KO, Abaka-Cann JE, Affram DE, Osae EA (2015) Prevalence of overweight and obesity among students in the kumasi metropolis. J Nutr Metab. [Crossref]
4. NCD Risk Factor Collaboration (NCD-RisC) (2016) Trends in adult body-mass index in 200 countries from 1975 to 2014: a pooled analysis of 1698 population-based measurement studies with 19·2 million participants. Lancet 387: 1377-1396. [Crossref]

5. Akbartabartoori M, Lean ME, Hankey CR (2008) The associations between current recommendation for physical activity and cardiovascular risks associated with obesity. Eur J Clin Nutr 62: 1-9. [Crossref]

6. Centers for disease control and prevention. Physical activity for everyone. (2017) http:// wwwcdcgov/physicalactivity/everyone/glossary/index.html

7. Booth FW, Roberts CK, Laye MJ (2012) Lack of exercise is a major cause of chronic diseases. Compr Physiol 2: 1143-1211. [Crossref]

8. Ahmad T, Chasman DI, Mora S, Pare G, Cook NR, et al. (2010) The fat-mass and obesity-associated (FTO) gene, physical activity, and risk of incident cardiovascular events in white women. Am Heart J 160: 1163-1169. [Crossref]

9. Beekley MD, Abe T, Kondo M, Midorikawa T, Yamauchi T (2006) Comparison of normalized maximum aerobic capacity and body composition of sumo wrestlers to athletes in combat and other sports. J Sports Sci Med 5: 13-20. [Crossref]

10. Gallus S, Lugo A, Murisic B, Bosetti C, Boffetta P, et al. (2015) Overweight and obesity in 16 European countries. Eur J Nutr 54: 679-689. [Crossref]

11. Medbø JI, Tabata I (1989) Relative importance of aerobic and anaerobic energy release during short-lasting exhausting bicycle exercise. J Appl Physiol 67: 1881-1886. [Crossref]

12. Slentz CA, Aiken LB, Houmard JA, Bales CW, Johnson JL, et al. (2005) Inactivity, exercise, and visceral fat. STRRIDE: a randomized, controlled study of exercise intensity and amount. J Appl Physiol 99: 1613-1618. [Crossref]

13. Little JP, Gillen JB, Percival ME, Safdar A, Tarnopolsky MA, et al. (2011) Lowvolume high-intensity interval training reduces hyperglycemia and increases muscle mitochondrial capacity in patients with type 2 diabetes. J Appl Physiol 111: 1554-1560. [Crossref]

14. Ellingsgaard H, Hauselmann I, Schuler B, Habib AM, Baggio LL, et al. (2011) Interleukin-6 enhances insulin secretion by increasing glucagon-like peptide-1 secretion from L cells and alpha cells. Nat Med 17: 1481-1489. [Crossref]

15. Finucane MM, Stevens GA, Cowan MJ, Danaei G, Lin JK, et al. (2011) National, regional, and global trends in body-mass index since 1980: sys- tematic analysis of health examination surveys and epidemio- logical studies with 960 country-years and 9.1 million participants. Lancet 377: 557-567. [Crossref]

16. World health organization: Obesity: Preventing and Managing the Global Epidemic. Report of a WHO consultation (WHO Technical Report Series 894) (2010) www.who. int/nutrition/publications/obesity/WHO_TRS_894/en/Accessed April 6, 2018.

17. Franks PW, Hanson RL, Knowler WC, Sievers ML, Bennett PH, et al. (2010) Childhood obesity, other cardiovascular risk factors, and premature death. $N$ Engl $J$ Med 362: 485-493. [Crossref]

18. Ross R, Dagnone D, Jones PJ, Smith H, Paddags A, et al. (2000) Reduction in obesity and related comorbid conditions after diet-induced weight loss or exercise-induced weight loss in men. A randomized, controlled trial. Ann Intern Med 133: 92-103. [Crossref]

19. Denou E, Marcinko K, Surette MG, Steinberg GR, Schertzer JD (2016) High-intensity exercise training increases the diversity and metabolic capacity of the mouse dista gut microbiota during diet-induced obesity. Am J Physiol Endocrinol Metab 310: E982-E993. [Crossref]

20. Lee IM, Shiroma EJ, Evenson KR, Kamada M, et al. (2018) Accelerometer-measured physical activity and sedentary behavior in relation to all-cause mortality: The women's health study. Circulation 137: 203-205. [Crossref]

Copyright: (C2018 Nakajima M. This is an open-access article distributed under the terms of the Creative Commons Attribution License, which permits unrestricted use, distribution, and reproduction in any medium, provided the original author and source are credited. 